\title{
Poleward bound: biological impacts of Southern Hemisphere glaciation
}

\author{
Ceridwen I. Fraser ${ }^{1}$, Raisa Nikula ${ }^{2 *}$, Daniel E. Ruzzante ${ }^{3 *}$ and Jonathan M. Waters ${ }^{2 *}$ \\ ${ }_{1}^{1}$ Lutte Biologique et Ecologie Spatiale, Université Libre de Bruxelles, 50 av FD Roosevelt - CP 160/12, 1050 Bruxelles, Belgium \\ ${ }^{2}$ Allan Wilson Centre for Molecular Ecology and Evolution, Department of Zoology, University of Otago, 340 Great King Street, \\ Dunedin 9016, New Zealand \\ ${ }^{3}$ Department of Biology, Dalhousie University, Halifax, NS B3H 4R2, Canada
}

\begin{abstract}
Postglacial recolonisation patterns are well documented for the Northern Hemisphere biota, but comparable processes in the Southern Hemisphere have only recently been examined. In the largely terrestrial Northern Hemisphere, recession of ice after the Last Glacial Maximum (LGM) allowed various taxa, including slow-moving terrestrial species, to migrate poleward. By contrast, the Southern Hemisphere polar region is completely ringed by ocean, and recolonisation of Antarctica and the sub-Antarctic islands has thus presented considerable challenges. Although a few highly dispersive marine species have been able to recolonise postglacially, most surviving high-latitude taxa appear to have persisted throughout glacial maxima in local refugia. These contrasting patterns highlight the importance of habitat continuity in facilitating biological range shifts in response to climate change.
\end{abstract}

High-latitude biological range shifts with past climate change

The high latitudes of the Southern Hemisphere: 'polar opposite' of the north

The geographic characteristics of the polar regions of the Southern and Northern Hemispheres are strikingly different from one another. The North Pole falls in an ocean ringed by continental land, whereas the South Pole sits in the middle of a continent surrounded by ocean (Box 1). Such contrasting environments present considerably different challenges to the associated high-latitude biota.

\section{Postglacial range shifts in the Northern Hemisphere: recognised patterns}

As Earth has undergone cycles of global climate change, organismal distributions have shifted in response, generally moving away from the poles during glacial periods, and towards the poles during interglacials [1]. Postglacial (see Glossary) recolonisation of territory made habitable by receding glaciers and warming temperatures is typically marked by a relative lack of genetic diversity in newly reestablished populations. This biogeographic pattern reflects both the young age of such populations and the rapid demographic expansion of 'leading-edge' colonists, effectively blocking the establishment of later immigrants [1-3]. In the Northern Hemisphere, major postglacial

\footnotetext{
Corresponding author: Fraser, C.I. (ceridwen.fraser@gmail.com)

These authors contributed equally to this article.
}

ranges shifts have been inferred for a wide variety of taxa, with many species moving from mid-latitude refugia to northern habitats or to higher altitudes [2]. Species can have highly individualistic responses to glacial-interglacial climate change, and patterns of postglacial range shifts thus vary greatly among taxa $[4,5]$. Nonetheless, although some high-latitude taxa appear to have survived locally throughout the last glaciation (sometimes referred to as persistence in 'cryptic refugia') [2,4-6], the overwhelming pattern in the temperate and polar Northern Hemisphere has been one of large latitudinal postglacial range shifts.

\section{Postglacial range shifts in the Southern Hemisphere: new frontiers}

In contrast to the wealth of literature addressing Northern Hemisphere climate change and biodiversity impacts, relatively few studies had, until recently, addressed the glacial-interglacial history of Southern Hemisphere ecosystems (but see [7]). Emerging data suggest that patterns in the comparatively oceanic Southern Hemisphere (Boxes 1 and 2) differ considerably from those of the Northern Hemisphere, particularly at the polar and subpolar (i.e., greater than approximately $50^{\circ} \mathrm{S}$ ) latitudes. At a time of

\section{Glossary}

Antarctic Circumpolar Current (ACC): the strongest ocean current in the world, which circles Antarctica in an easterly direction.

Antarctic Polar Front (APF): boundary between Antarctic and sub-Antarctic waters.

Cladogenesis: branching of an evolutionary lineage resulting in new taxa. Haplotype: a haploid genotype. A variant of DNA, inherited from one parent, which differs from other DNA variants on the same site of the genome by one or more nucleotide characters.

Last Glacial Maximum (LGM): the peak of the last Ice Age, approximately $18000-20000$ years ago.

Nunatak: an ice-free area (e.g., a rock or knob) protruding above glacial ice; or an exposed mountain peak.

Periglacial: area adjacent to an ice sheet and/or glacier.

Phylogeography: study of geographic distributions of genetic lineages and processes that shape them.

Polynya: area of open water surrounded by shelf or sea ice, often in the order of $100 \mathrm{~km}^{2}$; usually formed by warm upwelling.

Postglacial: subsequent to a glacial period. Most commonly used to refer to the time between the LGM and now.

Refugium: geographical area in which populations of glacially impacted organisms persisted during the LGM (e.g., an unglaciated valley).

Southern Ocean: ocean surrounding Antarctica, usually considered bounded to the north by the APF, but sometimes considered to include sub-Antarctic waters between the APF and the STC.

Subtropical Convergence (STC): boundary between sub-Antarctic and temperate waters. 
Box 1. General patterns of biological response to Quaternary climate change cycles in the Northern and Southern Hemisphere high latitudes

Although many Southern Hemisphere taxa were presumably forced to lower latitudes, or driven locally extinct, with the onset of Quaternary glaciations, few appear to have recolonised the high latitudes postglacially. The oceanic fronts and strong circumpolar currents encircling Antarctica can act as effective barriers to latitudinal biological dispersal $[26,27,53,91,92]$, and have probably prevented many taxa from dispersing to the Antarctic and sub-Antarctic regions during warm interglacial periods, with some exceptions $[93,94]$. Most taxa present in these southern regions are inferred to have persisted in local refugia throughout recent glaciations. By contrast, Northern Hemisphere taxa, both marine and terrestrial, highly mobile and sedentary, have experienced more dynamic histories, with major northward range shifts during interglacial periods in the absence of strong oceanographic barriers comparable to the southern ACC, APF and STC (although, in some cases, mountain ranges have limited their postglacial dispersal [1]) (Figure I).

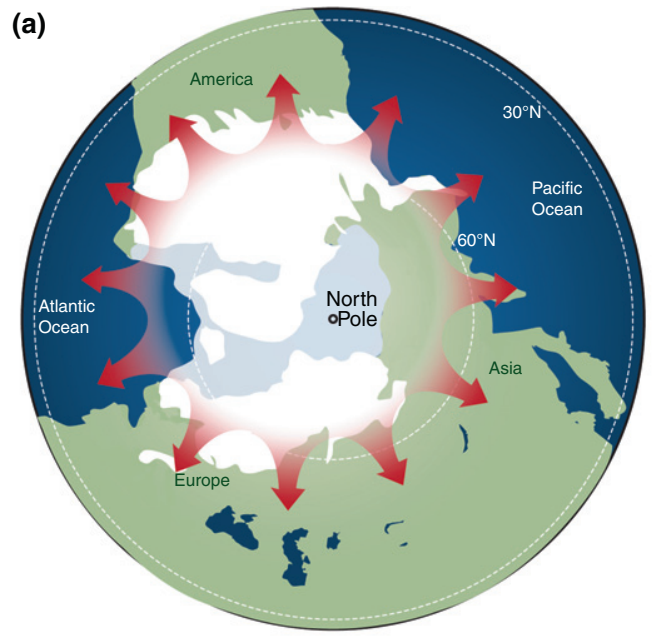

Quaternary glacial periods:

Expanding ice caps and cooling temperatures drive taxa towards equator

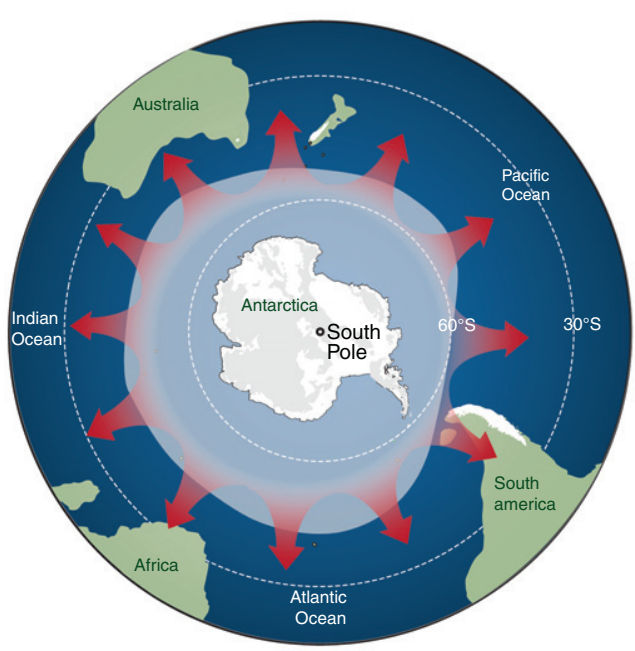

(b)

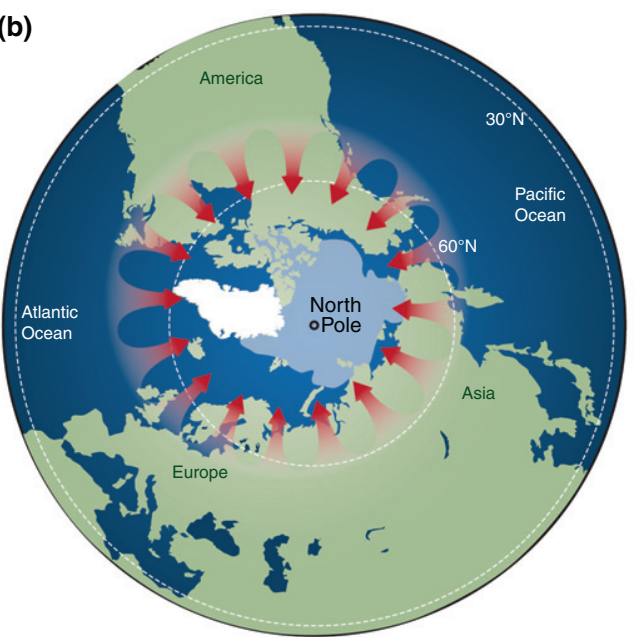

Quaternary interglacial periods:

Northern Hemisphere taxa move back towards poles, but poleward dispersal in Southern Hemisphere largely blocked by Southern Ocean currents and fronts

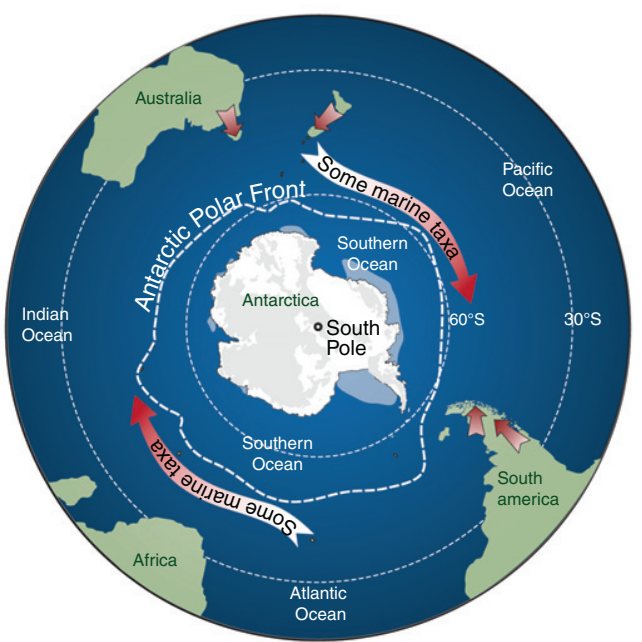

TRENDS in Ecology \& Evolution

Figure I. Broadly, whereas large latitudinal range shifts are inferred to have occurred postglacially in a wide range of taxa in the Northern Hemisphere, similar distributional changes have not occurred to the same extent in the high latitudes of the Southern Hemisphere. The oceanic North Pole is ringed by continental land, whereas the continent of Antarctica (Antarctic bedrock [95] indicated in grey) is surrounded by ocean with strong, circumpolar currents and fronts (Box 2). Red arrows show the generalised, inferred directions of biological distribution changes during glacial (a) and interglacial (b) periods. The approximate cover of continental glacial ice is indicated in white, and perennial sea ice in pale blue.

rapid, anthropogenically accelerated global warming [8], understanding the factors that facilitate or inhibit biological range shifts in response to climate change is critically important. Here, we review the predominant patterns of biological response in the Southern Hemisphere high latitudes (glaciated or sea ice-affected regions) to the interglacial warming that followed the LGM, from approximately 18000 years ago to the present day [9]. We consider the factors controlling high-latitude biodiversity shifts based on physical contrasts between the Northern and Southern hemispheres. We focus on biological range shifts in response to natural global warming, rather than anthropogenic invasions or human-mediated recent global warming, and primarily deal with taxa for which there is clear evidence of natural population expansion and/or range shifts since the LGM. Our focus is on the high 


\section{Box 2. Characteristics of Southern Hemisphere high latitudes}

Antarctica is a heavily glaciated continent, and parts of the surrounding ocean are covered by sea ice for much of the year, particularly in winter. Antarctica was thought to have been completely glaciated at the LGM, although new biological data indicate that some pockets of terrestrial habitat probably remained ice free [12].

The sub-Antarctic islands (here considered to be those occurring approximately between the STC and the APF, but also including South Georgia and Heard Island) have diverse geological and glacial histories. At the LGM, some islands are thought to have been fully glaciated, with ice probably extending offshore (e.g., Kerguelen and Heard Islands), whereas for others there is geological evidence that some terrestrial areas remained ice free (e.g., on Crozet, Falkland and Macquarie islands) [96]. However, in many cases, the extent of glaciation on sub-Antarctic islands remains poorly known (see [38]), and the possibility of LGM terrestrial glacial refugia cannot be dismissed for any. Antarctic winter sea ice extended considerably further north at the LGM than it does today and, although the precise extent of the ice is not known [50], there is some biological indication that it at least occasionally extended north to sub-Antarctic islands, such as Macquarie, Marion and Crozet Islands [46].

The ocean surrounding Antarctica (the Southern Ocean) connects the Atlantic, Pacific and Indian Oceans and is home to the strongest current in the world, the ACC, driven largely by intense westerly winds. Cold Antarctic waters meet warmer sub-Antarctic waters at the APF (also known as the Antarctic Convergence), and sub-Antarctic waters extend north to the STC (Figure I).

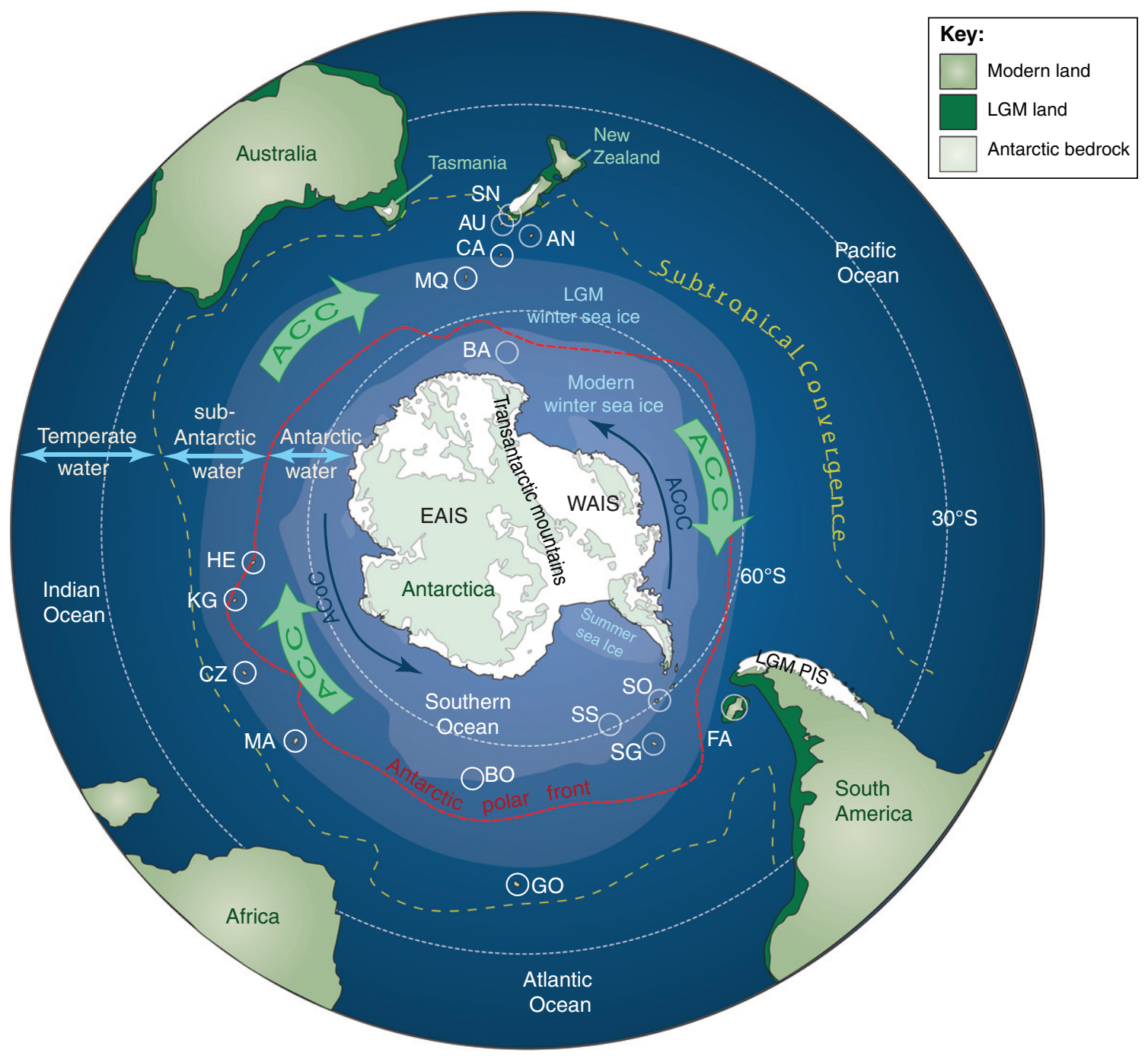

$\overline{T R E N D S}$ in Ecology \& Evolution

Figure I. Features of the Southern Hemisphere high latitudes, showing present-day oceanic fronts, sea-ice extent [97] and Antarctic bedrock [95] as well as key features at the Last Glacial Maximum (LGM). Some sub-Antarctic and Antarctic island locations are indicated by white circles; not labelled but indicated in white on the map are the New Zealand and Tasmanian ice sheets at the LGM. Hypothesised LGM winter sea-ice extent is approximately indicated, based on contemporary biological data [46] combined with microfossil data [50]. Abbreviations: ACC, Antarctic Circumpolar Current; ACoC, Antarctic coastal (counterclockwise) current; AU, Auckland Islands; AN, Antipodes Islands; BA, Balleny Island; BO, Bouvet Island; CA, Campbell Island; CZ, Crozet Islands; FA, Falkland Islands (also known as Malvinas); GO, Gough Island; HE, Heard Island; LGM PIS, Patagonian ice sheet at the LGM; KG, Kerguelen Islands; MA, Marion and Prince Edward Islands; MQ, Macquarie Island; SG, South Georgia; SN, Snares Islands; SO, South Orkney Islands; SS, South Sandwich Islands; WAIS and EAIS, West and East Antarctic ice sheets, respectively. 
latitudes, but we also include brief overviews of postglacial range shifts in other glaciated parts of Southern Hemisphere [i.e. New Zealand, Tasmania (Australia) and southern South America].

\section{Emerging patterns of postglacial range shifts in the Southern Hemisphere high latitudes}

Evidence for long-term in situ persistence of Antarctic terrestrial taxa

Only approximately $0.3 \%$ of Antarctica is currently ice free [10], and it has long been thought that little or no ice-free habitat could have existed at the LGM [11]. However, numerous recent studies provide evidence of deeply divergent lineages unique to Antarctica, indicating glacial survival in fragmented habitats followed by postglacial expansion, and pointing to long-term persistence of terrestrial taxa, such as arthropods, on the Antarctic continent [11-16]. The only evidence of postglacial recolonisation of the Antarctic from lower latitudes comes from highly dispersive marine mammals and seabirds (Box 3). Some endemic freshwater copepods and cladocerans appear to have survived the last Ice Age in Antarctica [12], and ancient lineages of Antarctic mites, estimated to have diverged from their non-Antarctic sister groups 6-10 million years ago (Mya), have presumably also persisted on the continent throughout numerous glacial periods [17]. The biogeographic history of the two vascular plant taxa native to Antarctica is not well understood, and whether they are ancient Gondwanan relicts or postglacial colonists has yet to be resolved [18]. For the non-vascular flora, many lichens $(33-50 \%)$ appear to be endemic, and so are

\section{Box 3. Postglacial recolonisation of Antarctica by marine mammals and seabirds}

Only for marine mammals and seabirds, capable of travelling long distances in short periods of time, have any large latitudinal range shifts been inferred in the Antarctic since the LGM. Species that require icy environments (ice obligates) should theoretically not have been particularly adversely impacted by Pleistocene glaciations, whereas those that form colonies on ice-free land (e.g., gentoo penguins, Adélie penguins, fur seals, elephant seals and sea lions) would have had to retreat to lower latitudes during glacial maxima, at least for breeding purposes. In the Northern Hemisphere, several Arctic marine mammals, although cold-adapted and highly dispersive, show signatures of classic south-to-north postglacial range shifts, with population segregation and bottlenecks inferred at the LGM [98]. A molecular study of extant and extinct sub-Antarctic and Antarctic elephant seal (Mirounga leonina) populations, a species that requires ice-free land to breed, indicates that an Antarctic continent (Victoria Land) population colonised the area when it was freed from ice 7500-8000 years ago, but was driven out by ice growth approximately 1000 years ago to again take refuge at lower-latitude Macquarie Island, where the species is still found [84] (Figure 1, main text). Similarly, with glacial shortage of coastal polynyas for feeding and ice-free land for nesting, it has been proposed that all Antarctic penguin species except the emperor (Aptenodytes forsteri) might have retreated to lower latitude (sub-Antarctic) refugia to breed during glacial maxima [25]. Genetic evidence indicates that modern Adélie penguins derive from two lineages, presumably from two refugial populations of uncertain location (but potentially within the Antarctic region) that expanded after the last ice age [99]. In contrast to penguins, some flighted seabirds, such as petrels, are able to nest on nunataks and fly to open-ocean polynyas to feed, and thus might well have persisted in situ throughout recent glacial periods [25]. likely to have survived recent glacial periods locally in Antarctica. By contrast, many mosses (6-7\% endemic) are proposed to be recent, potentially postglacial, colonists, possibly arriving via wind-driven propagule dispersal from neighbouring landmasses [19]. However, molecular work indicates that Antarctic moss endemism might currently be underestimated, and also provides evidence for Pleistocene persistence for some lineages in Victoria Land refugia (Figure 1) [20].

\section{Antarctic glacial refugia created by elevation and volcanism?}

The existence of ice-free pockets of terrestrial habitat throughout recent ice ages is supported by numerous molecular studies of Antarctic taxa, and possible locations of Antarctic ice-free terrestrial glacial refugia have been inferred from genetic evidence of ancient lineages [12] (Figure 1), yet geological evidence for such refugia remains scant [11]. Collapse of the West Antarctic Ice Sheet during some Pleistocene interglacials [21] might have created a more maritime environment close to the Transantarctic Mountains, promoting dispersal of terrestrial taxa during interglacials and thereby increasing their chances of glacial survival. Small ice-free areas, such as nunataks (e.g., in alpine regions such as the Transantarctic Mountains), probably existed during recent glacial periods, potentially providing refugia throughout the LGM for alpine taxa (e.g., the endemic montane mite family Maudheimiidae) [11]. However, nunatak fauna are primarily continental and alpine specialised; therefore, the persistence of lower altitude fauna throughout the LGM cannot easily be explained by nunataks [11]. Pockets of relatively warm, ice-free land within mouths of geothermal glacial caves, or areas around volcanoes made ice free by volcanic steam, could explain the glacial persistence of some Antarctic terrestrial taxa. There is presently an extensive geothermal cave system on the volcanic Mount Erebus in Antarctica and, on the sub-Antarctic South Sandwich Islands, geothermally warmed soils allow colonisation by a wider range of flora than in comparable unwarmed soils [22]. In the Northern Hemisphere, a subterranean amphipod species appears to have survived recent glacials in geothermally created refugia under the Icelandic ice cap [23]. If our hypothesis that some Antarctic glacial refugia were geothermal is correct, we predict that Antarctic geothermal caves should continue to house native terrestrial taxa today.

\section{Evidence for the long-term local persistence of Antarctic marine shelf taxa}

Populations of Antarctic marine taxa occupying continental shelf habitats are particularly vulnerable to glacial extirpation and therefore could be expected to have undergone wide-scale postglacial recolonisation. Three main scenarios have emerged regarding how such species survived glaciations: (i) persistence in periglacial 'moving' refugial regions; (ii) survival in the considerably more northern sub-Antarctic islands or southern South America; and (iii) retreat to shelf slope and deep-sea habitats.

The first scenario, in which severely contracted populations experienced repeated founding events as they moved 


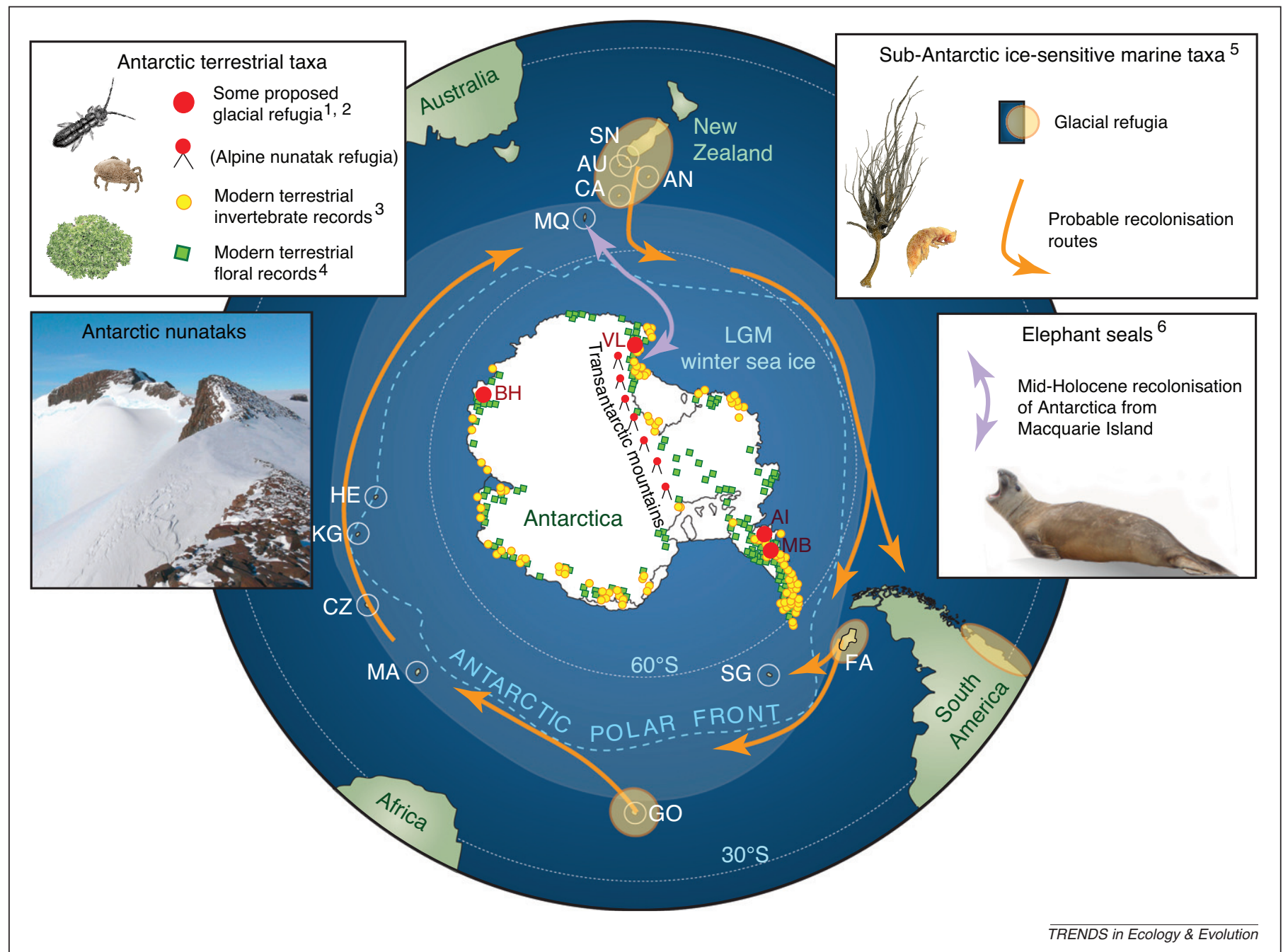

Figure 1. Proposed refugial regions and recolonisation routes. On the whole, few taxa appear to have dispersed to the Antarctic or sub-Antarctic regions from lower latitudes postglacially, probably because of the oceanic barriers isolating the Southern Hemisphere high latitudes. With some exceptions from highly dispersive taxa (see insets on the right), most taxa present in the high-latitude regions today are thought to have persisted in situ or in local refugia throughout Pleistocene glaciations, although many show genetic signatures of postglacial population expansions. A few of the Antarctic refugial regions suggested by ${ }^{1} \mathrm{Convey} \mathrm{et} \mathrm{al.} \mathrm{[12]} \mathrm{for} \mathrm{a} \mathrm{range} \mathrm{of} \mathrm{taxa,} \mathrm{and}{ }^{2} \mathrm{Hills}$ et al. [20] for a moss species, are shown. Abbreviations: Al, Alexander Island (nematodes and microbes); BH, Bunger Hills (freshwater copepods); MB, Marguerite Bay (arthropods); VL, Victoria Land (moss). ${ }^{3}$ Modern terrestrial invertebrate records, adapted from Figure 3 of McGaughran et al. 2011 [13]. ${ }^{4}$ Approximate locations of modern terrestrial floral records, adapted from Figure 2 of Peat et al. 2007 [19]. ${ }^{5}$ Low-latitude glacial refugia for sub-Antarctic marine organisms [i.e. regions where many 'subAntarctic' marine biota are found, but which were not affected by sea ice at the Last Glacial Maximum (LGM)], and probable recolonisation route/s via the Antarctic Circumpolar Current [46-48]. ${ }^{6}$ Mid-Holocene recolonisation of Antarctic mainland by elephant seals from sub-Antarctic refugia to which they again retreated approximately 1000 years ago [84]. Inset photo: Antarctic nunataks near SANAE base, reproduced with permission from Santjie du Toit. For definitions of island names, see Figure I, Box 2.

among unstable patches of ice-free benthic habitat [24], especially open-ocean polynyas [25], should be reflected in reduced genetic diversity within modern populations. Similar lack of diversity within populations would be expected under a hypothesis of north-to-south recolonisation, with the exception that source populations could have persisted until the present, and should thus show genetic affinities with re-established populations. By contrast, the deep-sea migration scenario should lead to distinct regional genetic structure, as the retreat into and out of refugia could have occurred on larger geographic scales with only limited bottlenecks.

In support of the 'moving' refugia hypothesis, recent studies on numerous species inhabiting the Antarctic shelf waters have revealed genetic patterns indicative of recent population size and/or range expansion from few (or a single) refugia of small effective population size [26-34]. However, some taxa exhibit pronounced geographic structuring, more suggestive of the deep-sea migration mode $[26,35,36]$. For both scenarios, a range of taxa with both low and high autonomous dispersal potential are represented, supporting the notion that the responses of species to climate change are highly individualistic [4], and do not necessarily depend on life-history characteristics such as pelagic larval duration. Whereas both the 'moving' refugia scenario and the 'depth shift' scenario are supported by molecular data, there is as yet no evidence for postglacial colonisation from significantly lower latitudes by Antarctic marine taxa. Lack of postglacial recolonisation of Antarctic waters from lower latitudes could largely result from an inability of taxa to traverse, or survive traversal of, the Antarctic Polar Front (APF) (Box 4).

\section{Recolonisation routes for Antarctic marine shelf taxa}

The major vectors for rapid postglacial recolonisation of Antarctic shelf areas freed by receding ice are the ocean 
Box 4. Marine biogeographical isolation by the Antarctic Polar Front

The permeability of the APF to north-south dispersal of marine taxa is not yet well understood. The position of the front is changeable, and has at times been significantly further north [100], perhaps facilitating occasional biotic dispersal events between Antarctica and South America. Indications from a range of studies also suggest that taxa have occasionally been able to disperse across the front via the deep sea [12], where the front is less of a barrier; however, evidence from shallower, shelf organisms is, as yet, scant [94]. Some taxa (e.g., some fish, crustaceans and bivalves) show evidence of having dispersed across the APF since its formation, but genetic divergences between lineages to the north and south of the front nonetheless appear to date back several million years [12], suggesting that traverses of this oceanic barrier occur only rarely, and/or that physiological limits currently prevent many cooltemperate taxa from surviving in the Southern Ocean [93,94]. Some recent observations of organisms traversing the front but failing to establish (reviewed by [94]) indicate that physiological constraints do probably have an important role in preventing colonisation of the region for some taxa. However, whereas there are several studies showing postglacial recolonisation of marine taxa in the Arctic or sub-Arctic [5], no studies have yet shown postglacial recolonisation of Antarctic waters from refugia north of the Southern Ocean, suggesting that a wide range of marine taxa struggle to cross this barrier. Marine benthic taxa in Antarctica are diverse and show evidence of long in situ evolution; therefore, on the whole, most can be inferred to have persisted in the polar region throughout recent glacial periods, either in transient refugia, such as polynyas, or in the deep sea [12].

current systems surrounding the continent; the counterclockwise Antarctic Coastal Current (ACoC), and the clockwise Antarctic Circumpolar Current (ACC) (Box 2). Interglacial collapses of the West Antarctic Ice Sheet [21] might also have provided a shortcut for circum-Antarctic dispersal of, and thus regional recolonisation by, marine species or lineages [34]. For example, dispersal via a trans-Antarctic seaway created by an interglacial ice-sheet collapse could explain genetic similarities between Weddell and Ross Sea populations of an octopod (Pareledone turqueti) [34] and a sea slug of the Doris kerguelensis complex [26]. The relative significance of circum-Antarctic population connectivity via either the ACC or the intermittent trans-Antarctic seaway remains to be tested with wide-scale and multispecies data sets.

\section{Evidence for long-term in situ persistence of terrestrial sub-Antarctic taxa}

Genetic evidence indicates persistence of several terrestrial taxa on sub-Antarctic islands throughout recent glacial periods, supporting a hypothesis of local terrestrial refugia (Box 2). For instance, numerous highly divergent mitochondrial DNA lineages within the endemic weevil group Ectemnorhinus have been found within and among subAntarctic islands, most of them estimated to have existed since long before the LGM [37]. Similarly, evidence of biotic persistence on sub-Antarctic islands has arisen from molecular studies of ameronothroid mites [17], and from palaeoecological and palaeoenvironmental data from a range of flowering plants, some endemic to the sub-Antarctic and hypothesised to be relicts of ancient Antarctic flora that took refuge on sub-Antarctic islands at the onset of Quaternary glaciations [38,39].
Although occasional dispersal among distant islands has been inferred from molecular data $[17,40]$, most usually via the predominantly eastward ocean and wind currents (West Wind Drift dispersal [41]) but also sometimes against the prevailing winds [37], there is as yet no evidence of terrestrial taxa dispersing to the sub-Antarctic postglacially from significantly lower latitudes. Indeed, the molecular evidence from mites not only indicates glacial persistence at high latitudes, but also that one Halozetes lineage has postglacially dispersed from the sub-Antarctic to lower-latitude continental Africa [17].

Glacial cycles (as well as volcanism and geological regionalisation) have nonetheless impacted the distributions of poorly dispersive sub-Antarctic terrestrial taxa. For example, studies on Marion Island show intra-island phylogenetic differences among populations of springtails [42], mites [43,44] and the cushion plant Azorella selago [45], with spatial patterns and estimated timing broadly consistent with a hypothesis of population segregation by advancing glaciers, followed by population expansion with glacial retreat. However, such impacts have been fairly localised, with some terrestrial refugial habitats inferred to have been available on Marion Island even during the LGM.

\section{Highly dispersive marine taxa recolonised the sub- Antarctic postglacially}

The sub-Antarctic islands harbour diverse shallow-marine and intertidal taxa, the more ice sensitive of which appear to be relatively new arrivals, most probably having recolonised the islands postglacially. Two ecologically important kelp taxa, southern bull-kelp, Durvillaea [46], and giant bladder kelp, Macrocystis [47], as well as kelp-associated brooding crustaceans Limnoria and Parawaldeckia $[48,49]$ show circumpolar haplotypes and near-negligible genetic diversity at high-latitude sub-Antarctic island locations versus relatively high diversity at lower latitudes. These findings are consistent with the expectations of classic models of postglacial recolonisation, 'southern richness to northern purity' [1], here reversed as 'northern richness to southern purity' for the Southern Hemisphere. Although current estimates of the extent of Antarctic winter sea ice at the LGM, based on diatom fossils in sea-floor sediment cores, are limited by a lack of data from some sub-Antarctic regions [50], genetic data from Durvillaea suggest LGM sea ice extended far enough north to have affected Macquarie, Kerguelen, Crozet and Marion Island shores (Box 2), and removed sub-Antarctic populations of ice-sensitive shallow-marine taxa [46]. Some kelpassociated taxa, such as isopods, amphipods [48] and limpets [51], are inferred to have subsequently rafted with buoyant kelps to achieve wide-scale postglacial dispersal and population expansion among sub-Antarctic islands.

\section{Possible glacial refugia for highly dispersive sub- Antarctic marine taxa}

Marine species that show evidence of having recolonised the sub-Antarctic islands postglacially probably retreated to relatively low-latitude glacial refugia, such as Gough Island, the Falkland Islands [48], or the New Zealand subAntarctic [46], regions that show relatively high levels of 
genetic diversity and distinct haplotypes for some taxa. Recolonisation probably followed the eastward path of the ACC (Figure 1). There is as yet no strong evidence that recolonisation of the sub-Antarctic occurred from populations along the cold-temperate western coast of South America; for bull-kelp, genetic evidence indicates that populations north of the ice-affected Patagonian region are isolated downstream of the sub-Antarctic by the north-flowing Humboldt Current [52].

\section{Evidence of glacial persistence in situ in poorly dispersive sub-Antarctic marine taxa}

In contrast to the evidence for recent recolonisation of the sub-Antarctic islands by some highly dispersive marine taxa, relatively poorly dispersive taxa that are not usually associated with buoyant material generally show deeper divergences, and even distinct species, among sub-Antarctic islands. For instance, the ice scour-resistant limpet genus Nacella, whose larvae are believed to settle within one month (too short a time to allow dispersal among most sub-Antarctic islands [49]), has several distinct species with distributions generally restricted to different subAntarctic islands and/or biogeographic regions [53]. There are considerably high levels of endemism in some marine invertebrate groups at sub-Antarctic islands (e.g., molluscs [54]), suggesting that numerous ice scour-resistant taxa, such as those able to shelter from ice in rock cracks, below boulders, or deep enough to avoid the ice foot, have persisted in the region throughout the LGM.

\section{Range shifts with recession of Pleistocene glaciers in New Zealand, Australia and South America}

Pleistocene ice ages led to the formation of glaciers on parts of New Zealand, Tasmania (southern Australia) and southern South America (Patagonia). At the LGM, a wedge-like glacier divided the southern and northern parts of the South Island of New Zealand. Tasmania became connected to the Australian mainland, its central parts arid and covered by an $1100-\mathrm{km}^{2}$ glacial ice cap, and the south Australian coastal currents were drastically altered. In southern South America, a large ice field covered the Andes from $35^{\circ} \mathrm{S}$ to the southern tip of South America, reaching the Pacific Ocean south of $39^{\circ} \mathrm{S}$, and extending east over much of the southern Patagonian steppe and Tierra del Fuego [55]. As in the Northern Hemisphere high latitudes [4], species in New Zealand, Australia and southern South America have responded to recent glacial cycles in a variety of ways. Although some cold-tolerant species survived in local refugia in glaciated regions, many taxa retreated to non-glaciated areas.

New Zealand Whereas some taxa apparently persisted in situ in the central South Island of New Zealand throughout the Pleistocene [56,57], genetic data and ecological niche modelling suggest many forest plants and terrestrial invertebrates were eliminated from much of the island during the LGM, with subsequent rapid expansion from various northern refugia [58-61]. Demographic reconstructions have revealed post-LGM population growth, sometimes involving east-west dispersal across the main divide of the South Island, the Southern Alps [59,62], as well as linear southward expansion [63,64]. A striking evolutionary effect of glaciations has been cladogenesis between northern and southern taxa in regions historically bisected by LGM glacial ice (e.g., some alpine insects [64,65] and trees [66]).

Tasmania (Australia) In southernmost Australia, on what is now the island of Tasmania, diversity gradients in chloroplast DNA of Eucalyptus trees indicate postglacial recolonisation of the glaciated region from south-eastern and northern refugia [67], and in an endemic rainforest tree, the Huon pine (Lagarostrobos franklinii), postglacial expansion is inferred to have occurred from a western refugium [68]. In the marine coastal realm, southern bull-kelp (Durvillaea potatorum) appears to have recolonised the western coast of Tasmania from a northern, mainland refugium with postglacial initiation of the Zeehan Current [69].

Patagonia (southern South America) Numerous coldtolerant taxa survived glacial periods in central and southern Patagonia in multiple local refugia west and east of the Andes (plants [70], rodents [71,72], lizards [70], frogs [73], fish [74,75], otters [76] and crabs [77]). In some cases, refugia were located west of the Andes within the areas presumed to have been covered by icefields (see [75-77]), suggesting the existence of gaps in ice cover [76], but other taxa exhibit phylogeographic patterns consistent with survival in large populations in periglacial refugia east of the Andes in southern Patagonia [78,79] and on the island of Tierra del Fuego $[71,72,80]$. Some of these taxa show evidence of population expansion at high latitudes following glacial periods $[79,80]$. Marine coastal refugia have also been invoked for marine-tolerant aquatic species [76,81]. Drainage reversals during glacial termination periods across the Andes affected phylogeographic patterns in galaxiid fishes [75,81], and increases in river connectivity with low sea levels facilitated latitudinal dispersal among percichthyid fish $[82,83]$. Moderate latitudinal range shifts occurred in the distributions of plant and vertebrate species, with three main refugial areas identified: valleys north of $36^{\circ} \mathrm{S}$; peripheral refugia east of the Andes between $39^{\circ} \mathrm{S}$ and $43^{\circ} \mathrm{S}$; and higher latitude lowland refugia up to $51^{\circ} \mathrm{S}$ [70] (Figure 2).

\section{Concluding remarks and predictions}

\section{Lack of postglacial recolonisation from lower latitudes}

In contrast to the Northern Hemisphere, where postglacial recolonisation of high-latitude regions has occurred from low-latitude refugia in a wide range of taxa, the oceanically isolated southern polar and subpolar regions have had little biological input since the LGM from lower latitudes. We note three exceptions to this generalisation: (i) iceaffected shallow-marine organisms capable of rafting (e.g., kelp and associated invertebrates) have dispersed postglacially to the sub-Antarctic islands from more northern refugia [46,48]; (ii) at least one marine mammal that requires ice-free land to breed (the elephant seal) recolonised the Antarctic postglacially from a sub-Antarctic refugium [84]; and (iii) a low degree of endemism suggests that many Antarctic moss species are relatively recent 


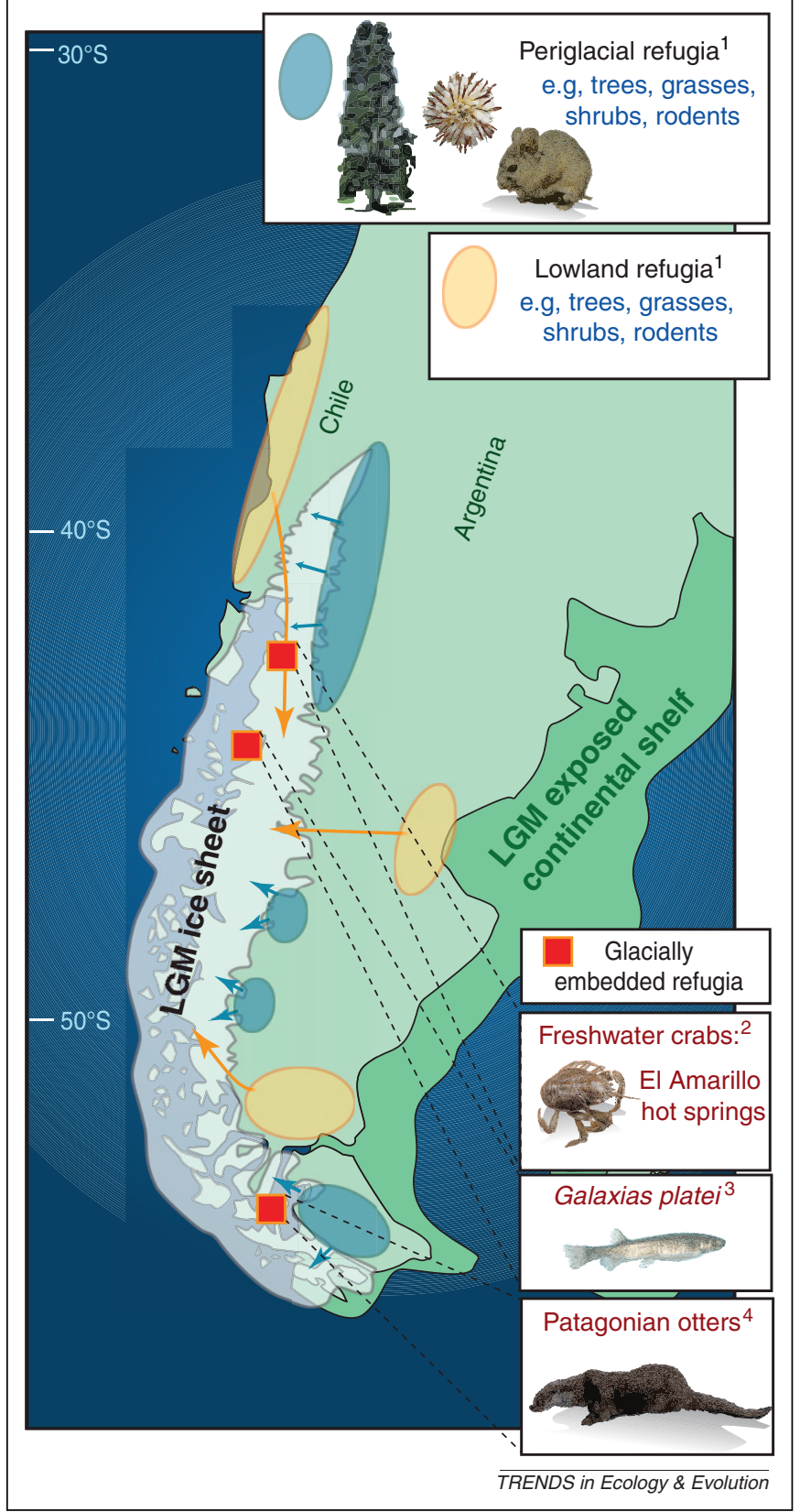

Figure 2. Generalised glacial refugia and postglacial recolonisation routes in southern South America. Although some taxa appear to have persisted throughout the Last Glacial Maximum (LGM) in local refugia, even in areas within or close to the boundaries of the ice sheet, many taxa (including trees and mammals) were driven to the north or the east of the ice sheet and only recolonised the region postglacially; this pattern is similar to that seen in the Northern Hemisphere for many taxa. ${ }^{1}$ Periglacial and lowland refugial regions based mainly on data from plants, such as Chilean cedar, Nothofagus trees, Hordeum grasses and flowering shrubs; and terrestrial vertebrates such as small rodents [70]. ${ }^{2}$ Refugium inferred for freshwater crabs Aegla alacalufi in geothermal springs that might have kept localised areas ice free [77]. ${ }^{3}$ LGM refugium inferred for the fish Galaxias plate within the area affected by the Patagonian Ice Sheet [75]. ${ }^{4}$ Molecular data suggest that the otter Lontra provocax survived the LGM in glacial refugia in the southern fiords and channels of Chile [76].

colonists of the continent [19] (but see [20]). Low levels of glaciation on sub-Antarctic islands compared with land at equivalent latitudes in the Northern Hemisphere might be a result of oceanic climate buffering, and could help to account for the relatively high levels of LGM persistence observed in numerous terrestrial sub-Antarctic taxa.

Most present-day native terrestrial Antarctic taxa are inferred to have persisted throughout recent glacial periods in localised high-latitude refugia. Many other terrestrial taxa were apparently driven off the Antarctic continent more than 1.8 Mya [10], perhaps partly by expanding ice at the onset of Quaternary glaciations 2.6 Mya, and since then, the depauperate Antarctic terrestrial assemblages have not been replenished from lower latitude sources. By contrast, northern (Arctic) polar regions have comparatively taxon-rich terrestrial assemblages [85], even including high-order vertebrates, such as reindeer and the arctic fox. However, 'traditional' (Northern Hemisphere-type) low- to high-latitudinal range shifts have occurred in the more trans-latitudinal landmasses of New Zealand and South America. Therefore, the rarity of taxa showing evidence of postglacial range expansion to Antarctica and the sub-Antarctic islands appears to be largely a consequence of the isolation of the region from other landmasses by the Southern Ocean, thermal fronts and strong circumpolar currents.

\section{Future southward range shifts predicted to be blocked by the Southern Ocean}

Most climate scientists agree that the Earth is currently undergoing rapid, anthropogenically accelerated climate change [8], with an expected global warming over coming decades of several degrees, potentially leading to significant loss of the polar ice sheets [86]. With global warming, organismal distributions are expected to slide increasingly poleward [87]. During the warm 'greenhouse' climate of the Eocene (when global temperatures averaged $10-15{ }^{\circ} \mathrm{C}$ higher than today), Antarctica was home to diverse flora and fauna, including subtropical forests, but the continent was not isolated, as it is today, by strong encircling ocean currents; the Drake Passage began to open during the Eocene or Oligocene, and intensification of the ACC only occurred during the Miocene [88]. The failure of many taxa to disperse to the Antarctic continent and sub-Antarctic islands from lower latitudes since the LGM should act as a warning that, in the Southern Hemisphere, there is a limit to how far south the ranges of temperate species will be able to shift before they are blocked by the Southern Ocean. Indeed, recent studies of southward range shifts induced by global warming in Australian marine algae and fish indicate that many species are likely to go locally or completely extinct as they are driven off the southern edge of the continent in coming years $[89,90]$. Based on differences in postglacial range shifts in the Northern versus Southern Hemisphere high latitudes, we predict relatively high levels of extinction in the Southern Hemisphere, as the climate warms and temperate and subpolar organisms are unable to achieve adequately large latitudinal range shifts.

\section{Acknowledgements}

We thank Godfrey Hewitt, Peter Convey and two anonymous reviewers and Paul Craze for comments that helped improve the manuscript. We apologise to the authors of several relevant papers that could not be included in this review owing to space restrictions. We acknowledge support from the Fonds National de la Recherche Scientifique (FNRS) of Belgium (C.I.F.), the Allan Wilson Centre for Molecular Ecology and Evolution, New Zealand (R.N. and J.M.W.), and a Canadian NSERC Discovery grant (D.E.R.). Thanks to Santjie du Toit (South African National Antarctic Program) for the nunatak photograph inset in Figure 1. D.E.R. thanks S. Walde for discussions and C.I.F. thanks Bruno Danis for technical advice. 


\section{References}

1 Hewitt, G. (2000) The genetic legacy of the Quaternary ice ages. Nature 405, 907-913

2 Hewitt, G.M. (2004) Genetic consequences of climatic oscillations in the Quaternary. Philos. Trans. R. Soc. Lond. Ser. B 359, 183-195

3 Waters, J.M. (2011) Competitive exclusion: phylogeography's 'elephant in the room'? Mol. Ecol. 20, 4388-4394

4 Stewart, J.R. et al. (2010) Refugia revisited: individualistic responses of species in space and time. Proc. R. Soc. B: Biol. Sci. 277, 661-671

5 Maggs, C.A. et al. (2008) Evaluating signatures of glacial refugia for North Atlantic benthic marine taxa. Ecology 89, S108-S122

6 Provan, J. and Bennett, K.D. (2008) Phylogeographic insights into cryptic glacial refugia. Trends Ecol. Evol. 23, 564-571

7 Chown, S.L. et al. (1998) Ecological biogeography of Southern Ocean islands: species-area relationships, human impacts, and conservation. Am. Nat. 152, 562-575

8 Anderegg, W.R.L. et al. (2010) Expert credibility in climate change. Proc. Natl. Acad. Sci. U.S.A. 107, 12107-12109

9 Denton, G.H. et al. (2010) The Last Glacial Termination. Science 328, $1652-1656$

10 Convey, P. and Stevens, M.I. (2007) Antarctic biodiversity. Science 317, 1877-1878

11 Convey, P. et al. (2008) Antarctic terrestrial life - challenging the history of the frozen continent? Biol. Rev. 83, 103-117

12 Convey, P. et al. (2009) Exploring biological constraints on the glacial history of Antarctica. Quat. Sci. Rev. 28, 3035-3048

13 McGaughran, A. et al. (2011) Extreme glacial legacies: a synthesis of the Antarctic springtail phylogeographic record. Insects 2, 62-82

14 McGaughran, A. et al. (2010) Biogeography of circum-Antarctic springtails. Mol. Phylogenet. Evol. 57, 48-58

15 De Wever, A. et al. (2009) Hidden levels of phylodiversity in Antarctic green algae: further evidence for the existence of glacial refugia. Proc. R. Soc. B: Biol. Sci. 276, 3591-3599

16 Allegrucci, G. et al. (2006) A molecular phylogeny of Antarctic chironomidae and its implications for biogeographical history. Polar Biol. 29, 320-326

17 Mortimer, E. et al. (2011) Mite dispersal among the Southern Ocean Islands and Antarctica before the Last Glacial Maximum. Proc. $R$. Soc. B: Biol. Sci. 278, 1247-1255

18 Mosyakin, S. et al. (2007) Origins of native vascular plants of Antarctica: comments from a historical phytogeography viewpoint. Cytol. Genet. 41, 308-316

19 Peat, H.J. et al. (2007) Diversity and biogeography of the Antarctic flora. J. Biogeogr. 34, 132-146

20 Hills, S.F.K. et al. (2010) Molecular support for Pleistocene persistence of the continental Antarctic moss Bryum argenteum. Antarct. Sci. 22, 721-726

21 Pollard, D. and DeConto, R.M. (2009) Modelling West Antarctic Ice Sheet growth and collapse through the past five million years. Nature 458, 329-332

22 Convey, P. et al. (2000) The flora of the South Sandwich Islands, with particular reference to the influence of geothermal heating. $J$. Biogeogr. 27, 1279-1295

23 Kornobis, E. et al. (2010) Molecular evidence of the survival of subterranean amphipods (Arthropoda) during Ice Age underneath glaciers in Iceland. Mol. Ecol. 19, 2516-2530

24 Thatje, S. et al. (2005) On the origin of Antarctic marine benthic community structure. Trends Ecol. Evol. 20, 534-540

25 Thatje, S. et al. (2008) Life hung by a thread: endurance of Antarctic fauna in glacial periods. Ecology 89, 682-692

26 Wilson, N.G. et al. (2009) Ocean barriers and glaciation: evidence for explosive radiation of mitochondrial lineages in the Antarctic sea slug Doris kerguelenensis (Mollusca, Nudibranchia). Mol. Ecol. 18, 965984

27 Janosik, A. et al. (2011) Evolutionary history of Southern Ocean Odontaster sea star species (Odontasteridae; Asteroidea). Polar Biol. 34, 575-586

28 Hoffman, J.I. et al. (2011) Strong population genetic structure in a broadcast-spawning Antarctic marine invertebrate. J. Hered. 102, 5566

29 Hunter, R.L. and Halanych, K.M. (2008) Evaluating connectivity in the brooding brittle star Astrotoma agassizii across the Drake Passage in the Southern Ocean. J. Hered. 99, 137-148

30 González-Wevar, C.A. et al. (2011) Phylogeography and demographic inference in Nacella (Patinigera) concinna (Strebel, 1908) in the western Antarctic Peninsula. Deep Sea Res. Part II: Top. Stud. Oceanogr. 58, 220-229

31 Thornhill, D.J. et al. (2008) Open-ocean barriers to dispersal: a test case with the Antarctic Polar Front and the ribbon worm Parborlasia corrugatus (Nemertea: Lineidae). Mol. Ecol. 17, 5104-5117

32 Raupach, M.J.et al. (2010) Genetic homogeneity and circum-Antarctic distribution of two benthic shrimp species of the Southern Ocean, Chorismus antarcticus and Nematocarcinus lanceopes. Mar. Biol. 157, 1783-1797

33 Hemery, L.G. et al. (2012) Comprehensive sampling reveals circumpolarity and sympatry in seven mitochondrial lineages of the Southern Ocean crinoid species Promachocrinus kerguelensis (Echinodermata). Mol. Ecol. 21, 2502-2518

34 Strugnell, J.M. et al. (2012) Persistent genetic signatures of historic climatic events in an Antarctic octopus. Mol. Ecol. 21, 2775-2787

35 Hunter, R.L. and Halanych, K.M. (2010) Phylogeography of the Antarctic planktotrophic brittle star Ophionotus victoriae reveals genetic structure inconsistent with early life history. Mar. Biol. $157,1693-1704$

36 Hoffman, J.I. et al. (2011) Effects of brooding and broadcasting reproductive modes on the population genetic structure of two Antarctic gastropod molluscs. Mar. Biol. 158, 287-296

37 Grobler, G.C. et al. (2011) Cryptic species, biogeographic complexity and the evolutionary history of the Ectemnorhinus group in the subAntarctic, including a description of Bothrometopus huntleyi, n. sp. Antarct. Sci. 23, 211-224

38 Van der Putten, N. et al. (2010) Subantarctic flowering plants: preglacial survivors or post-glacial immigrants? J. Biogeogr. 37, 582592

39 Wagstaff, S.J. et al. (2011) Evolution and biogeography of Pleurophyllum (Astereae, Asteraceae), a small genus of megaherbs endemic to the subantarctic islands. Am. J. Bot. 98, 62-75

40 Stevens, M.I. et al. (2006) Southern hemisphere springtails: could any have survived glaciation of Antarctica? Mol. Biol. Evol. 23, 874-882

41 Waters, J.M. (2008) Driven by the West Wind Drift? A synthesis of southern temperate marine biogeography, with new directions for dispersalism. J. Biogeogr. 35, 417-427

42 Myburgh, M. et al. (2007) Population structure, propagule pressure, and conservation biogeography in the sub-Antarctic: lessons from indigenous and invasive springtails. Divers. Distrib. 13, 143-154

43 Mortimer, E. and van Vuuren, B.J. (2007) Phylogeography of Eupodes minutus (Acari: Prostigmata) on sub-Antarctic Marion Island reflects the impact of historical events. Polar Biol. 30, 471-476

44 Mortimer, E. et al. (2012) Phylogeography of a mite, Halozetes fulvus, reflects the landscape history of a young volcanic island in the subAntarctic. Biol. J. Linn. Soc. 105, 131-145

45 Mortimer, E. et al. (2008) Growth form and population genetic structure of Azorella selago on sub-Antarctic Marion Island. Antarct. Sci. 20, 381-390

46 Fraser, C.I. et al. (2009) Kelp genes reveal effects of subantarctic sea ice during the Last Glacial Maximum. Proc. Natl. Acad. Sci. U.S.A. 106, 3249-3253

47 Macaya, E.C. and Zuccarello, G.C. (2010) Genetic structure of the giant kelp Macrocystis pyrifera along the southeastern Pacific. Mar. Ecol. Prog. Ser. 420, 103-112

48 Nikula, R. et al. (2010) Circumpolar dispersal by rafting in two subantarctic kelp-dwelling crustaceans. Mar. Ecol. Prog. Ser. 405, $221-230$

49 Fraser, C.I. et al. (2011) Oceanic rafting by a coastal community. Proc. R. Soc. B: Biol. Sci. 278, 649-655

50 Gersonde, R. et al. (2005) Sea-surface temperature and sea ice distribution of the Southern Ocean at the EPILOG Last Glacial Maximum - a circum-Antarctic view based on siliceous microfossil records. Quat. Sci. Rev. 24, 869-896

51 Reisser, C.M.O. et al. (2011) Connectivity, small islands and large distances: the Cellana strigilis limpet complex in the Southern Ocean. Mol. Ecol. 20, 3399-3413

52 Fraser, C. et al. (2010) Contemporary habitat discontinuity and historic glacial ice drive genetic divergence in Chilean kelp. $B M C$ Evol. Biol. 10, 203 
53 González-Wevar, C.A. et al. (2010) Molecular phylogeny and historical biogeography of Nacella (Patellogastropoda: Nacellidae) in the Southern Ocean. Mol. Phylogenet. Evol. 56, 115-124

54 Linse, K. et al. (2006) Biodiversity and biogeography of Antarctic and sub-Antarctic mollusca. Deep Sea Res. Part II: Top. Stud. Oceanogr. $53,985-1008$

55 Rabassa, J. et al. (2011) Late Cenozoic glaciations in Patagonia and Tierra del Fuego: an updated review. Biol. J. Linn. Soc. 103, 316335

56 Hill, K.B.R. et al. (2009) Surviving glacial ages within the Biotic Gap: phylogeography of the New Zealand cicada Maoricicada campbelli. J. Biogeogr. 36, 675-692

57 Marske, K.A. et al. (2011) Reconciling phylogeography and ecological niche models for New Zealand beetles: looking beyond glacial refugia. Mol. Phylogenet. Evol. 59, 89-102

58 Gardner, R.C. et al. (2004) A late Quaternary phylogeography for Metrosideros (Myrtaceae) in New Zealand inferred from chloroplast DNA haplotypes. Biol. J. Linn. Soc. 83, 399-412

59 Marske, K.A. et al. (2009) Phylogeography and ecological niche modelling implicate coastal refugia and trans-alpine dispersal of a New Zealand fungus beetle. Mol. Ecol. 18, 5126-5142

60 Buckley, T.R. et al. (2010) Phylogeography and ecological niche modelling of the New Zealand stick insect Clitarchus hookeri (White) support survival in multiple coastal refugia. J. Biogeogr. 37, 682-695

61 Buckley, T.R. et al. (2009) Identifying glacial refugia in a geographic parthenogen using palaeoclimate modelling and phylogeography: the New Zealand stick insect Argosarchus horridus (White). Mol. Ecol. 18, 4650-4663

62 Craw, D. et al. (2008) Evolution of biological dispersal corridors through a tectonically active mountain range in New Zealand. $J$. Biogeogr. 35, 1790-1802

63 Marshall, D.C. et al. (2011) Hybridization, mitochondrial DNA phylogeography, and prediction of the early stages of reproductive isolation: lessons from New Zealand cicadas (genus Kikihia). Syst. Biol. 60, 482-502

64 Wallis, G.P. and Trewick, S.A. (2009) New Zealand phylogeography: evolution on a small continent. Mol. Ecol. 18, 3548-3580

$65 \mathrm{McCulloch}, \mathrm{G} . \mathrm{A}$. et al. (2010) Onset of glaciation drove simultaneous vicariant isolation of alpine insects in New Zealand. Evolution 64, 2033-2043

66 Leschen, R.A.B. et al. (2008) Determining the origin and age of the Westland beech (Nothofagus) gap, New Zealand, using fungus beetle genetics. Mol. Ecol. 17, 1256-1276

67 McKinnon, G.E. et al. (2004) Glacial refugia and reticulate evolution: the case of the Tasmanian eucalypts. Philos. Trans. R. Soc. B 359, $275-284$

68 Clark, C.M. and Carbone, I. (2008) Chloroplast DNA phylogeography in long-lived Huon pine, a Tasmanian rain forest conifer. Can. J.Forest Res. 38, 1576-1589

69 Fraser, C.I. et al. (2009) Glacial oceanographic contrasts explain phylogeography of Australian bull kelp. Mol. Ecol. 18, 2287-2296

70 Sérsic, A.N. et al. (2011) Emerging phylogeographical patterns of plants and terrestrial vertebrates from Patagonia. Biol. J. Linn. Soc. 103, 475-494

71 Lessa, E.P. et al. (2010) Genetic footprints of late Quaternary climate change in the diversity of Patagonian-Fueguian rodents. Mol. Ecol. 19, 3031-3037

72 Pardiñas, U.F.J. et al. (2011) The evolutionary history of sigmodontine rodents in Patagonia and Tierra del Fuego. Biol. J. Linn. Soc. 103, 495-513

73 Nuñez, J.J. et al. (2011) Amphibian phylogeography in the Antipodes: refugia and postglacial colonization explain mitochondrial haplotype distribution in the Patagonian frog Eupsophus calcaratus (Cycloramphidae). Mol. Phylogenet. Evol. 58, 343-352

74 Ruzzante, D.E. et al. (2008) Climate control on ancestral population dynamics: insight from Patagonian fish phylogeography. Mol. Ecol. $17,2234-2244$

75 Zemlak, T.S. et al. (2008) Across the southern Andes on fin: glacial refugia, drainage reversals and a secondary contact zone revealed by the phylogeographical signal of Galaxias platei in Patagonia. Mol. Ecol. 17, 5049-5061
76 Vianna, J.A. et al. (2011) Phylogeography of the Patagonian otter Lontra provocax: adaptive divergence to marine habitat or signature of southern glacial refugia? BMC Evol. Biol. 11, 53

$77 \mathrm{Xu}$, J.W. et al. (2009) Pleistocene glaciation leaves deep signature on the freshwater crab Aegla alacalufi in Chilean Patagonia. Mol. Ecol. $18,904-918$

78 Jakob, S.S. et al. (2009) Phylogeographic analyses and paleodistribution modeling indicate Pleistocene in situ survival of Hordeum species (Poaceae) in Southern Patagonia without genetic or spatial restriction. Mol. Biol. Evol. 26, 907-923

79 Tremetsberger, K. et al. (2009) Pleistocene refugia and polytopic replacement of diploids by tetraploids in the Patagonian and Subantarctic plant Hypochaeris incana (Asteracea, Cichorieae). Mol. Ecol. 18, 3668-3682

80 Premoli, A.C. et al. (2010) Southern-most Nothofagus trees enduring ice ages: genetic evidence and ecological niche retrodiction reveal high latitude (54 degrees S) glacial refugia. Palaeogeogr. Palaeocl. 298, $247-256$

81 Zemlak, T.S. et al. (2010) Surviving historical Patagonian landscapes and climate: molecular insights from Galaxias maculatus. BMC Evol. Biol. 10, 67

82 Ruzzante, D.E. et al. (2006) Phylogeography of the Percichthyidae (Pisces) in Patagonia: roles of orogeny, glaciation, and volcanism. Mol. Ecol. 15, 2949-2968

83 Ruzzante, D.E. et al. (2011) Phylogeography and phenotypic diversification in the Patagonian fish Percichthys trucha: the roles of Quaternary glacial cycles and natural selection. Biol. J. Linn. Soc. 103, 514-529

84 de Bruyn, M. et al. (2009) Rapid response of a marine mammal species to Holocene climate and habitat change. PLoS Genet. 5, e1000554

85 Pugh, P.J.A. and Convey, P. (2008) Surviving out in the cold: Antarctic endemic invertebrates and their refugia. J. Biogeogr. 35, 2176-2186

86 Bertler, N.A.N. and Barrett, P.J. (2010) Vanishing polar ice sheets. In Changing Climates, Earth Systems and Society (Dodson, J., ed.), pp. 49-83, Springer

87 Hickling, R. et al. (2006) The distributions of a wide range of taxonomic groups are expanding polewards. Global Change Biol. $12,450-455$

88 Lagabrielle, Y. et al. (2009) The tectonic history of Drake Passage and its possible impacts on global climate. Earth Planet Sci. Lett. 279, $197-211$

89 Wernberg, T. et al. (2011) Seaweed communities in retreat from ocean warming. Curr. Biol. 21, 1828-1832

90 Last, P.R. et al. (2011) Long-term shifts in abundance and distribution of a temperate fish fauna: a response to climate change and fishing practices. Global Ecol. Biogeogr. 20, 58-72

91 Wilson, N. et al. (2007) Multiple lineages and absence of panmixia in the 'circumpolar' crinoid Promachocrinus kerguelensis from the Atlantic sector of Antarctica. Mar. Biol. 152, 895-904

92 Diaz, A. et al. (2011) Evolutionary pathways among shallow and deepsea echinoids of the genus Sterechinus in the Southern Ocean. Deep Sea Res. Part II: Top. Stud. Oceanogr. 58, 205-211

93 Aronson, R.B. et al. (2007) Climate change and invasibility of the Antarctic benthos. Annu. Rev. Ecol. Evol. S 38, 129-154

94 Clarke, A. et al. (2005) How isolated is Antarctica? Trends Ecol. Evol. $20,1-3$

95 Lythe, M.B. et al. (2001) BEDMAP: a new ice thickness and subglacial topographic model of Antarctica. J. Geophys. Res. Sol. Ea 106, 1133511351

96 Hall, K. (2004) Quaternary glaciation of the sub-Antarctic Islands. In Quaternary Glaciations - Extent and Chronology, Part III (Ehlers, J. and Gibbard, P.L., eds), pp. 339-345, Elsevier

97 Cavalieri, D.J. and Parkinson, C.L. (2008) Antarctic sea ice variability and trends, 1979-2006. J. Geophys. Res. Oceans 113, c07004

98 O'Corry-Crowe, G. (2008) Climate change and the molecular ecology of Arctic marine mammals. Ecol. Appl. 18, S56-S76

99 Ritchie, P.A. et al. (2004) Ancient DNA enables timing of the Pleistocene origin and Holocene expansion of two Adélie penguin lineages in Antarctica. Mol. Biol. Evol. 21, 240-248

100 Kemp, A.E.S. et al. (2010) Migration of the Antarctic Polar Front through the mid-Pleistocene transition: evidence and climatic implications. Quat. Sci. Revi. 29, 1993-2009 